\title{
AS COMPREENSÕES DE EDUCAÇÃO AMBIENTAL E EDUCAÇÃO PROFISSIONAL NO CURSO DE TECNOLOGIA EM GESTÃO AMBIENTAL DO IFSUL
}

Christiano Nogueira ${ }^{1}$

Susana Inês Molon²

Resumo: Este artigo apresenta o resultado de uma pesquisa sobre as compreensões de Educação Ambiental e Educação Profissional de onze concluintes do curso de Tecnologia em Gestão Ambiental do Instituto Federal Sul-rio-grandense. Os alunos foram entrevistados e metodologicamente utilizou-se a Análise de Conteúdo. Os resultados mostram que há compreensões de uma cisão existente entre o homem e a natureza, o trabalho como exploração da natureza causando impactos e a formação relacionada aos interesses mercadológicos. Essas compreensões implicam perspectivas de uma Educação Ambiental voltada ao mercado por meio da conscientização para diminuir os impactos ambientais e de uma Educação Profissional voltada ao processo produtivo.

Palavras-chave: Educação Ambiental; Educação Profissional; Gestão Ambiental.

${ }^{1}$ Professor do Programa de Pós-graduação em Rede para o Ensino das Ciências Ambientais/Universidade Federal do Paraná. E-mail: christiano@ufpr.br

${ }^{2}$ Professora do Programa de Pós-graduação em Educação Ambiental/Universidade Federal do Rio Grande. E-mail: susana.molon@furg.br 


\section{Introdução}

A formação de tecnólogos na área ambiental está inserida em um contexto de diferentes interesses políticos, econômicos e sociais, que atende a demandas específicas, como em órgãos públicos e privados, com ações de mitigação, educação ambiental etc., voltadas a um mercado cuja força de trabalho, no contexto de uma sociedade capitalista, é a única mercadoria que o trabalhador pode vender, com vistas ao desenvolvimento do capitalismo. Em uma perspectiva oposta, atende à construção de uma sociedade com sujeitos vivendo de forma igualitária e de forma equilibrada com o meio ambiente, por meio de uma relação metabólica entre o homem e natureza ${ }^{3}$.

Nesse sentido, este artigo trata das concepções de homem ${ }^{4}$, de natureza e de trabalho, que implicam perspectivas de Educação Ambiental e de Educação Profissional do curso de Tecnologia em Gestão Ambiental do campus Pelotas-Visconde da Graça, no Instituto Federal Sul-rio-grandense.

O curso de Tecnologia em Gestão Ambiental teve início em 2009, quando 0 atual campus Pelotas-Visconde da Graça era, ainda, o Conjunto Agrotécnico "Visconde da Graça", vinculado à Universidade Federal de Pelotas. A formação de tecnólogo é uma modalidade de graduação de nível superior que se concentra em uma área específica, e a titulação conferida no curso investigado é a de Tecnólogo em Gestão Ambiental. Desde sua criação, até hoje, foram construídos três projetos pedagógicos: o primeiro em 2009, o segundo em 2010, e o atual em 2012. No início, a duração prevista do curso era de seis semestres, com carga horária total de 2.465 horas, em regime acadêmico semestral. Desde o início, o turno de funcionamento é o diurno e o número de vagas ofertadas é de 40 por semestre. No projeto pedagógico de 2010, reconstruído devido à vinculação ao Instituto Federal Sul-rio-grandense, a carga horária foi alterada para 2.665 horas, ainda com número de seis semestres para sua conclusão e com regime semestral. $O$ projeto pedagógico vigente do curso em questão apresenta uma carga horária total de 2.130 horas, com duração de cinco semestres, também com regime semestral.

Homem, natureza e trabalho são concepções que fazem parte de uma totalidade em que a Educação Ambiental e a Educação Profissional englobam conjuntamente o processo formativo de tecnólogos e podem possibilitar a transformação das relações sociais em que o trabalho e a natureza sejam tratados a partir das necessidades básicas do homem, e não segundo uma perspectiva mercadológica.

\footnotetext{
${ }^{3}$ A relação metabólica entre o homem e a natureza tratada aqui é a relação em que o homem, ao interagir com a natureza, transforma-a; por sua vez, esta transformada transforma o homem como um processo de humanização da natureza (MARX, 1996).

${ }^{4} \mathrm{O}$ conceito de homem vem da construção teórica de Marx e, conforme poderá ser visto na sequência de leitura deste artigo, está inserido em concepções de autonomia e emancipação no processo formativo que contempla compreensões de igualdade de raça, cor, gênero, direcionamento sexual etc.
}

Revbea, São Paulo, V. 13, No 2: 195-213, 2018. 


\section{Procedimentos metodológicos}

Os alunos participantes, num total de onze, cursavam o último ano, pois se entendeu que, após o processo formativo ocorrido nos dois primeiros anos, eles já possuíam construídas concepções de homem, natureza e trabalho e, por sua vez, sobre Educação Ambiental e Educação Profissional.

As entrevistas ocorreram sem imprevistos entre 31 de março e 9 de abril de 2014, no campus Pelotas-Visconde da Graça. Como base para as entrevistas, um questionário foi utilizado. A entrevista classifica-se, segundo Gil (2008), como uma entrevista por pautas, já que tem como característica certo grau de estruturação, pois o pesquisador "se guia por uma relação de pontos de interesse que o entrevistador vai explorando ao longo do curso" (GIL, 2008, p. 117).

As perguntas deste questionário foram direcionadas para conhecer os efeitos práticos do currículo dos cursos; compreender como os alunos vivenciam a prática de sua futura profissão; compreender como ocorre o processo interdisciplinar nos cursos; compreender como os alunos entendem a relação entre o homem e a natureza; compreender como os alunos poderiam resolver problemas de questões ambientais considerando fatores políticos, econômicos e sociais; compreender o significado de meio ambiente e natureza; e verificar o que eles entendem por Educação Ambiental.

Durante as entrevistas, além de serem gravadas, foram realizadas anotações, mediante autorização do entrevistado. As entrevistas foram transcritas e, após essa etapa, realizou-se a leitura desses documentos, a análise e comentários dos sujeitos entrevistados para a categorização das informações, que posteriormente foram organizados em planilhas.

A análise e interpretação das informações da entrevista foram baseadas na Análise de Conteúdo (BARDIN, 1977; FRANCO, 2005). Esse método envolve um processo em que, numa primeira etapa, os textos originais passam pela desconstrução, que consiste no exame detalhado e na fragmentação do texto em unidades de base; posteriormente, pela categorização, que estabelece uma nova relação entre essas unidades de base, permitindo que sejam agrupados elementos semelhantes e também condições para uma maior profundidade na análise e interpretação dos dados.

\section{O Referencial Teórico}

Para uma melhor análise das concepções de homem, de natureza e de trabalho, e as perspectivas de Educação Ambiental e de Educação Profissional do curso tratado, apresentamos separadamente essas duas perspectivas.

\section{A Educação Ambiental}

$\mathrm{Na}$ Educação Ambiental, há atualmente diferentes descrições, mapeamentos das correntes, assim como são várias identificações, classificações e definições das suas diversas tendências. A caracterização de 
Educação Ambiental está influenciada por diferentes concepções epistemológicas de meio ambiente e natureza, que são constituídas por diversos contextos e situações sociais, políticas e históricas. A partir disso, apresentamos algumas descrições de autores que realizaram estudos aprofundados e podem contribuir significativamente para essa compreensão.

Sauvé (2005) apresenta uma cartografia das correntes de Educação Ambiental em um contexto norte-americano e europeu. Segundo essa autora, a noção de corrente refere-se a uma maneira geral com que se concebe a prática da Educação Ambiental. Embora cada corrente possua um conjunto de características específicas, diferenciando-se umas das outras, algumas compartilham características comuns, ou seja, não são mutuamente excludentes. A autora considera nessa cartografia, para não correr o risco de deformar a realidade, que seja uma classificação em categorias sem obedecer a uma rigidez. A seguir são apresentadas aquelas com maior destaque no cenário da Educação Ambiental e pertinentes ao contexto que envolve esta pesquisa.

A corrente Conservacionista/Recursista está centrada em proposições relacionadas à "conservação" dos recursos, seja quanto à qualidade ou quanto à quantidade. "Quando se fala de 'conservação da natureza', como biodiversidade, trata-se, sobretudo, de uma natureza-recurso. Há uma preocupação com a "administração do meio ambiente" ou, melhor dizendo, de gestão ambiental' (SAUVÉ, 2005, p. 20). Os programas de Educação Ambiental centrados nos três "R", muito conhecidos, quais sejam Redução, Reutilização e Reciclagem, são contemplados nessa concepção de Educação Ambiental.

A corrente Resolutiva de Educação Ambiental envolve estudos das problemáticas ambientais levando em consideração componentes sociais e biofísicos com suas controvérsias inerentes. A visão central de Educação Ambiental dessa corrente é a proposta pela UNESCO no contexto de seu Programa Internacional de Educação Ambiental (1975-1995).

A corrente da Sustentabilidade possui um enfoque com limitação mais naturalista, sem contemplar preocupações sociais, particularmente as econômicas, ao tratar das problemáticas ambientais; a educação para o desenvolvimento sustentável seria uma forma de amenizar esta carência. Assim, nessa perspectiva, a Educação Ambiental é tratada como política econômica. Assim, a formação de recursos humanos que favoreçam mudanças sociais e econômicas deve responder às necessidades da sustentabilidade.

As características dessas correntes apresentam uma natureza desvinculada do homem, pois aparecem ao proporem uma aproximação com a natureza, uma preservação dos recursos naturais, a reciclagem, um tratamento científico etc. Trata-se de uma perspectiva de Educação Ambiental que legitima a atual organização social, permitindo a consolidação de uma "naturalização" das diferenças de classes e do processo produtivo, que possui relação direta com o meio ambiente. Mesmo que perspectivas como essas envolvam 
abordagens interdisciplinares e transdisciplinares com aspectos sociais, não tratam a processualidade existente na relação entre o homem e a natureza. $O$ trabalho humano não é considerado como agente de transformação da natureza pelo homem e consequente possibilidade de transformação da sociedade.

A perspectiva de Educação Ambiental categorizada como Ecopedagogia é compreendida com base no pensamento crítico e inovador, promovendo a transformação e a construção da sociedade, envolvendo a individualidade e a coletividade em uma perspectiva holística com foco interdisciplinar na relação entre o ser humano e a natureza (RUSCHEINSKY, 2004; AVANZI 2004). Na Ecopedagogia, a Educação Ambiental deve estimular a solidariedade, a igualdade e o respeito aos direitos humanos, ajudando a desenvolver uma consciência ética em relação a todas as formas de vida, respeitando seus ciclos vitais e impondo limites à exploração dessas formas de vida. Nessa perspectiva, a Educação Ambiental envolve aspectos que promovem uma mudança social, visando à superação das forças opressoras, possibilitando a igualdade entre sujeitos e uma relação equilibrada entre o homem e a natureza.

A concepção de Educação Ambiental Crítica é defendida por alguns autores brasileiros com diferenças em suas construções teóricas. São apresentadas a seguir as abordagens de Isabel Carvalho, Mauro Guimarães e Carlos Frederico Loureiro sobre essa concepção.

Para Carvalho (2004), uma das autoras que se destaca nesse paradigma, a concepção de Educação Ambiental Crítica é apresentada como superação da visão ingênua da Educação Ambiental. Segundo essa autora, a Educação Ambiental é considerada legítima devido à especificidade da prática educativa ambientalmente orientada e seu papel crítico ao compreender as relações entre a sociedade e a natureza para intervir em problemas e conflitos ambientais. Aspectos políticos e pedagógicos da Educação Ambiental Crítica poderiam possibilitar uma mudança de valores e atitudes que contribuiria para a formação de um sujeito ecológico. Os sujeitos formados estariam orientados por sensibilidades solidárias com o meio social e ambiental, servindo como modelo para a formação de sujeitos e grupos sociais com capacidades de identificar, problematizar e agir em relação às questões socioambientais, com a finalidade de uma ética preocupada com a justiça ambiental.

Para Carvalho (2004), a prática educativa da Educação Ambiental Crítica é formar o sujeito em sua dimensão individual e social, considerando-o como um sujeito histórico. Os fundamentos teóricos desta autora, embora considerem o sujeito histórico com uma formação crítica, não consideram a formação dos sujeitos a partir do processo dialético com vistas à superação das relações de produção na sociedade capitalista.

A Educação Ambiental Crítica para Guimarães (2004) é uma construção teórica no sentido de contrapor algo existente no sentido de superar outra perspectiva categorizada como Educação Ambiental Conservadora.

revista brasileira educação ambiental 
Segundo Guimarães (2004), a Educação Ambiental Conservadora está relacionada à compreensão e postura educacional, a partir de um paradigma e ideologia que se manifestam hegemonicamente na constituição da sociedade atual. A Educação Ambiental Crítica desse autor fundamenta-se em ideias de que a Educação Ambiental Conservadora (sob o ponto de vista epistemológico, presa em suas perspectivas ideológicas) não é instrumentalizada e comprometida com o processo de transformações significativas da realidade socioambiental.

Para superação dessa perspectiva, Guimarães (2004) desenvolve a concepção de Educação Ambiental Crítica como aquela necessária para que haja uma ação educativa, com capacidade de transformação da realidade social e do meio ambiente, que está em crise, segundo processos históricos. Essa perspectiva de Educação Ambiental direcionaria para a superação de uma sociedade com tendência fragmentária, dualista e dicotômica.

A Educação Ambiental Crítica, para Loureiro (2009), que possui como foco a Educação Transformadora, é aquela em que há a compreensão de que a apreensão da realidade deve ocorrer a partir de categorias conceituais sem dissociação de procedimentos pedagógicos. A Educação Ambiental deve considerar o contexto envolvido ao abordar um conceito ou temática em que o global possui um significado de conjunto das relações em que estamos inseridos. No contexto multidimensional, há uma percepção do ser humano como um ser biológico, social, psicológico, cultural etc., que vive em sociedade, com sua historicidade e o complexo "enquanto união de elementos distintos inseparavelmente constitutivos do todo" (LOUREIRO, 2009, p. 93-94). Aspectos políticos devem fazer parte da Educação Ambiental; no processo formativo dos sujeitos, deve se considerar uma construção de concepções de homem, natureza e trabalho com vistas a promover uma transformação na sociedade com igualdade social e equilíbrio ambiental.

A Educação Ambiental Emancipatória e Transformadora é outra possibilidade de definição na perspectiva de Quintas (2004) e de Loureiro (2004, 2009). Esta é desenvolvida nos processos de gestão ambiental por Quintas (2004) e é aquela comprometida em construir um futuro sustentável que possua como fundamento o meio ambiente, entendido como ecologicamente equilibrado e direito de todos, bem de uso comum e essencial à qualidade de vida saudável. Nessa perspectiva, a Educação Ambiental implica a construção de uma sociedade com um estilo de desenvolvimento com justiça social e ambientalmente seguro, em um contexto de oposição à dependência econômica e exclusão social. O processo educativo nessa perspectiva se estrutura no sentido de superação da compreensão de uma realidade fragmentada através de uma construção e reconstrução que envolve um processo reflexivo entre os sujeitos envolvidos; respeitando a pluralidade e diversidade cultural com fortalecimento da ação coletiva e organizada, articulando os diferentes saberes e fazeres para proporcionar a compreensão dos problemas ambientais em toda a sua complexidade. 
A Educação Ambiental, segundo Loureiro (2004), é caracterizada para fins didáticos, por blocos de tendências, como Educação Ambiental Convencional e Educação Ambiental Transformadora. A Educação Ambiental Convencional é compreendida na individualidade dos sujeitos e está baseada em vivências práticas de sensibilização. As relações sociais são tratadas como baixa compreensão ou de forma secundária. Os processos educativos são tratados como atos comportamentais com pouca articulação com o coletivo e problematização para transformação da realidade de vida, sendo assim tais processos despolitizados. Nessa perspectiva há uma ingenuidade de que as mudanças objetivas ocorram a partir das mudanças individuais em que não há compreensão das relações sociais mais complexas. Há um tratamento do sujeito como um organismo biológico sem sua historicidade. Isso ocorre por meio do que Loureiro chamou de "biologização" do ser social. Assim, a responsabilidade pela degradação do meio ambiente é posta a um ser humano genérico, idealizado, a-histórico, que seria descontextualizado socialmente (LOUREIRO, 2004).

Dessa forma, segundo esse autor, a mudança pelos processos educativos para a superação da Educação Ambiental Convencional seria possível com a Educação Ambiental Transformadora. Nesta, para Loureiro (2004), a formação do sujeito deve contemplar a capacidade crítica junto com a compreensão de que ele faz parte da natureza e de que suas decisões, conjuntamente com outros sujeitos, implicam de forma direta ou indireta o meio ambiente. Essa compreensão para os sujeitos deve ocorrer com liberdade e sem as influências coercitivas. A Educação Ambiental Transformadora, para Loureiro (2009, p. 89), "é aquela que possui um conteúdo emancipatório, em que a dialética entre forma e conteúdo se realiza de tal maneira que as alterações da atividade humana, vinculadas ao fazer educativo, impliquem em mudanças".

Nessa perspectiva, a Educação Ambiental não pode ignorar o conflito de interesses nas relações existentes entre diferentes grupos sociais, com seus respectivos interesses que também são diferentes. Não há na Educação Ambiental Transformadora soluções compatibilistas existentes entre capitalismo e meio ambiente, e também encaminhamentos de ordem moral que desvinculem o comportamento dos indivíduos de sua historicidade.

Apresentadas as cartografias e concepções de Educação Ambiental utilizadas como fundamento desta pesquisa, a seguir são apresentadas as concepções de Educação Profissional utilizadas também como fundamento.

\section{A Educação Profissional}

Historicamente, a Educação Profissional passou por transformações significativas, mostrando-se como um espaço de disputa política. De um lado, com perspectivas de formação fragmentada de base tecnicista; por outro, que envolvem a emancipação e autonomia no processo formativo por meio de currículos integrados. 
As tratativas que envolvem a elaboração de currículos integrados na Educação Profissional são complexas, necessitando de uma discussão ampla com toda a comunidade onde os cursos estão inseridos. Devem contemplar, ainda no processo formativo, a autonomia e a emancipação dos sujeitos formados. A Educação Profissional deve ser analisada considerando o contexto social, político e econômico da sociedade que obedece a um modo de produção em que há uma cisão entre o trabalho intelectual e o trabalho manual. Isso, por sua vez, oculta uma materialidade que é a divisão da sociedade em classes que disputam uma hegemonia (FRIGOTTO, 2007; FRIGOTTO; CIAVATTA; RAMOS, 2005; KUENZER, 2006, 2010).

Frigotto (2007) aponta para a interpretação de uma educação baseada na desigualdade e tratada como produto e condição do projeto dominante da sociedade brasileira. "Para a burguesia brasileira não há a necessidade de universalização da Educação Básica, e sua relação com a Educação Profissional e Tecnológica é que esta seja restrita para formar o "cidadão produtivo" submisso e adaptado às necessidades do capital e do mercado" (FRIGOTTO, 2007, p. 1131).

Esse modelo está baseado em um capitalismo dependente dos grandes centros financeiros, o qual, em uma análise histórica e crítica do processo do trabalho, propicia a fetichização das relações na venda da força de trabalho nas relações sociais que são concebidas com naturalidade como se não dependessem da ação humana. A possibilidade de superação dessa relação entre o capital e 0 trabalho envolve a elaboração de currículos na Educação Profissional que contemplem no processo formativo a autonomia e emancipação dos sujeitos.

Essas dificuldades podem ser superadas, como apontam muitos estudos de pesquisadores da relação Trabalho e Educação (FRIGOTTO; CIAVATTA; RAMOS, 2005; KUENZER; GRABOWSKI, 2006), o que significa a possibilidade de, concretamente, implantar uma formação que contemple aspectos da ciência, tecnologia, cultura, artes, com as dimensões ontológicas do trabalho humano e as relações de produção. Trata-se de uma formação com uma perspectiva revolucionária.

Além disso, é importante destacar que as dificuldades para uma formação com aspectos críticos também podem estar relacionadas à instrução do professor. Em muitos casos, a formação crítica pode ser apresentada de forma impositiva aos professores que, além de não a conhecerem conceitualmente, podem possuir ainda concepções conservadoras sob o ponto de vista pedagógico e político a respeito dessa perspectiva. Tais aspectos dificultam a compreensão de uma educação com autonomia e emancipação com foco no trabalhador. Também as condições materiais, as formas de gestão das instituições que, muitas vezes, não ocorre de forma democrática, fomentam essas dificuldades, além da parcela de professores relacionados ao trabalho precarizado, como os professores substitutos, o que dificulta o seu envolvimento com essa perspectiva. 
Ainda nos últimos anos observa-se na Educação Profissional uma crescente expansão, principalmente com a Lei 11.892/08, que criou os Institutos Federais de Educação, Ciência e Tecnologia. Nessa lei, a finalidade dos Institutos Federais é ofertar Educação Profissional e Tecnológica em todos os níveis e modalidades e promover a integração e a verticalização da Educação Profissional, desde a Educação Básica até a Educação Superior, com objetivo de otimizar a infraestrutura física, dos quadros de pessoal e dos recursos de gestão. Também por meio dessa lei os Institutos Federais devem constituir-se como centros de excelência na oferta do ensino de ciências, em geral, e de ciências aplicadas, em particular, e também qualificar-se como referência no apoio à oferta do ensino de ciências nas instituições públicas de ensino e também capacitação técnica e atualização aos docentes.

Analisando a lei que cria os Institutos Federais, verifica-se a significativa proximidade com os setores produtivos, já que os Institutos Federais devem gerar e adaptar soluções sob o ponto de vista técnico e tecnológico, gerando benefício aos arranjos produtivos locais, ou seja, os Institutos Federais estão direcionados aos interesses do capitalismo. Para Otranto (2010, p. 11), "os institutos federais são, em última análise, mais um modelo alternativo à "universidade de pesquisa", que vem sendo implementado na América Latina, nos últimos anos, a partir do incentivo explícito do Banco Mundial".

Ainda segundo a autora, na proposta político-educacional-financeira do Banco Mundial, de criação de instituições de educação superior que tenham custos inferiores aos das universidades, como é o caso dos cursos tecnológicos, ganha especial destaque a alegação de que esses cursos seriam mais flexíveis, portanto mais integrados ao sistema produtivo, e de menor custo que o universitário tradicional.

A criação dos cursos superiores de tecnologia, com a Resolução CNE/CP 3, de 18 de dezembro de 2002, está relacionada com essa perspectiva de cursos mais flexíveis e mais integrados ao sistema produtivo. Conforme seu artigo 10, possui como objetivo a garantia aos cidadãos à aquisição de competências profissionais que os tornem aptos para a inserção em setores profissionais nos quais haja utilização de tecnologias. Também como características, conforme seu Artigo 20, destaca-se que esses cursos devem incentivar a capacidade empreendedora e permitir que os futuros profissionais compreendam e avaliem impactos sociais, econômicos e ambientais como resultado da produção de novas tecnologias. Ou seja, embora no contexto de sua criação a perspectiva para esses cursos fosse emancipatória, no contexto atual assume outra perspectiva que está diretamente em ressonância com os interesses associados às formas mais modernas do capitalismo mundial. 


\section{Apresentação e análise dos dados}

$\mathrm{Na}$ análise das entrevistas, foi utilizada a Análise de Conteúdo. Após a leitura e releitura das respostas dos entrevistados, os dados, identificados como unidades de registro, foram novamente agrupados segundo respostas afins, visando à compreensão das vozes que se manifestavam no conteúdo obtido. A partir dessa interpretação, emergiram as seguintes categorias gerais: homem, natureza e trabalho. As unidades de análise que as compõem são: Homem produz impactos à natureza; Relação trabalho, emprego e natureza; e Perspectiva interdisciplinar.

Os alunos tiveram seus nomes mantidos em sigilo, conforme solicitação. Assim, eles estão identificados por códigos, que foram atribuídos de maneira aleatória, sem qualquer relação com a sequência real da realização das entrevistas, de GA1 a GA11.

A unidade de análise "Homem produz impactos à natureza" mostra que a compreensão dos alunos está inserida em uma lógica em que há uma cisão entre o homem e a natureza. A opinião do participante GA6 expressa tal compreensão:

Como que eu vou dizer? A natureza, o ser humano vive nela, só que com o passar dos anos ele tá se aproveitando cada vez mais dela, diminuindo é, as espécies, tem muita espécie em extinção, aumentando o impacto ambiental. Então, a natureza tem para as pessoas viverem nela, só que tá de um modo que tá piorando cada vez mais, né (Part. GA6).

A cisão entre o homem e a natureza aparece também de outra forma, na fala dos alunos, quando abordam as atribuições do Tecnólogo em Gestão Ambiental. O participante GA3 assim se expressa a respeito disso:

É, gerenciamento de uma atividade visando à diminuição dos impactos ambientais, aumento dos lucros das empresas, e trabalhar com políticas ambientais em municípios, por exemplo, trabalhar com a questão de políticas públicas para conscientização ambiental, enfim (Part. GA3).

Ao expressar que, nas atribuições do gestor ambiental, está diminuir impactos ambientais com o aumento dos lucros das empresas, ele mostra uma compreensão que está em acordo com a lógica capitalista. Trata-se de considerar possível conciliar o que seria contraditório, ou seja, uma lógica de produção para o consumo com os recursos limitados existentes na natureza. É um entendimento de que o homem parece estar à parte da natureza, que não expressa, conforme Foster (2011), uma relação metabólica entre o homem e a natureza.

Da mesma forma, essa compreensão de cisão entre o homem e a natureza é corroborada ao se expressar a Educação Ambiental como forma de Revbea, São Paulo, V. 13, № 2: 195-213, 2018. 
conscientização para diminuir o impacto ambiental. Conforme a opinião do participante GA10:

Educação Ambiental é o ato de conscientizar e orientar as pessoas pra que elas, que elas estejam informadas de problemas no meio ambiente e do que elas podem fazer pra contribuir para não degradar, para não acabar por, degradando mais do que já está (Part. GA10).

A compreensão de que a Educação Ambiental é um ato de conscientizar e orientar as pessoas para diminuir os impactos ambientais não está de acordo com uma compreensão de superação da ideologia dominante. As falas apresentadas expressam compreensões associadas à corrente Conservacionista/Recursista e à corrente Resolutiva de Educação Ambiental, descritas por Sauvé (2005), bem como às concepções da Educação Ambiental Convencional, criticadas por Loureiro (2009) e Guimarães (2004), pois, quando se trata de conservar a natureza, considera-a como natureza-recurso. Sob o ponto de vista epistemológico, os comportamentos individuais não possuem uma instrumentalização, não ocorrendo transformações significativas da realidade, já que são tratados como atos comportamentais com pouca articulação coletiva (GUIMARÃES, 2004).

Nas compreensões que se expressam nessas falas, não há um comprometimento com transformações significativas da realidade, já que envolvem processos que são tratados como atos comportamentais, nos quais há pouca articulação com 0 coletivo e problematização com vistas à transformação da realidade de vida, fazendo assim com que esses processos não englobem aspectos políticos das questões ambientais.

A cisão entre o homem e a natureza que emergiram nas entrevistas pode indicar uma perspectiva de Educação Profissional em que há uma cisão também entre o trabalho manual e o trabalho intelectual. Isso porque não aparece nas falas um direcionamento do processo formativo envolvendo a discussão crítica que permita a compreensão do papel existente do modo de produção capitalista na atuação profissional. A opinião do participante GA10 expressa bem tais concepções, ao descrever sua atividade profissional:

Ah, eu acho que primeiramente ser ético, se trabalhar numa indústria ter ética de planejar e organizar as ações dentro dela voltadas para o meio ambiente, né. Também, também pra gestão, pro crescimento da indústria mais, e conservar, preservar o meio ambiente conforme for atuar, conforme o campo de atuação (Part. GA10). 
Essas compreensões mostram que o processo de alienação, sustentado pela ideologia dominante, distorce a característica humana de interação com a natureza com um foco voltado ao consumo e não às necessidades humanas reais. Ocorre uma centralidade e cultura no consumo, promovidas pelo capitalismo, que faz as pessoas perderem as ligações estreitas com a natureza (MAGDOFF \& FOSTER, 2011). Conforme Marx (1996), o produto do trabalho e a relação do trabalhador com a produção tornam-se estranhos ao homem e à natureza.

$\mathrm{Na}$ unidade de análise "Relação trabalho, emprego e natureza", a compreensão de trabalho e emprego pelos alunos também demonstra uma visão que está de acordo com a ideologia dominante, como o trabalho vinculado a uma renda, realização pessoal e/ou obrigações. Isso aparece na opinião do participante $\mathrm{GA3}$, quando diz que:

Trabalho para mim é uma tarefa. Alguma coisa que eu tenho que atingir, um desempenho. Uma atividade que eu exerço (Part. GA3).

Posteriormente, em sua fala sobre o que é emprego, assim se expressa:

É uma situação. Por exemplo, se tu quer procurar emprego ou tu quer procurar trabalho é diferente. Se for procurar um emprego, tu procura uma estabilidade, onde tu vai ter uma remuneração, enfim quando tu quer procurar trabalho, além de acrescentar pra ti, vai ter estabilidade do emprego mas vai estar exercendo uma atividade que tu goste, enfim (Part. GA3).

Esse participante faz uma diferenciação entre trabalho e emprego relacionando o primeiro a uma atividade de que a pessoa goste; já o segundo relaciona-se à estabilidade, em que também recebe uma remuneração. Embora haja uma diferenciação, não aparece explicitamente o trabalho, ou mesmo a compreensão de emprego, como uma relação de interação coletiva entre os sujeitos e a natureza:

A fala do participante GA11 mostra uma diferenciação semelhante, pois, para ele, trabalho:

É realizar uma atividade individualmente ou em grupo que tem a finalidade de atingir um objetivo, uma meta (Part. GA11).

E emprego: 
[...] emprego pra mim, tu tem que tá sendo remunerado por aquilo e trabalho não necessariamente (Part. GA11).

São compreensões semelhantes, em que o trabalho é visto como uma atividade e o emprego vinculado ao recebimento de uma remuneração. Aqui também não aparece explicitamente o trabalho como uma relação metabólica entre o homem e a natureza.

A visão, tanto de trabalho quanto de emprego, apresenta uma compreensão distorcida da realidade. Trata-se de uma alienação em que o emprego está relacionado a um processo de fetichização, em que há exploração do trabalhador, de forma que ele não se identifique no processo de produção. Não há uma compreensão do trabalho ontologicamente, ou seja, como um processo em que há um metabolismo existente entre o homem e a natureza (MARX, 1996).

A respeito da relação entre o trabalho e o meio ambiente, o participante GA4 assim se expressa:

Sim, com certeza. Se tu for ter que trabalhar, tu vai indiretamente, tu vai influenciar o meio onde a gente vive. É isso que eu entendo, se tu precisa daquele sustento, se tu precisa daquele local pra, pra, pra desenvolver, enfim, pra reproduzir né, que é o sistema tradicional do homem, e aí no caso, meio ambiente e trabalho acabam um indiretamente influenciando o outro (Part. GA4).

Esse participante encontrou dificuldades para expressar a diferença entre natureza e meio ambiente, mas apresentou uma compreensão da relação entre o trabalho e o meio ambiente. Embora ele tenha expressado que um influencia o outro, essa compreensão não apresenta outras informações que permitam entender que isso ocorra através de uma processualidade, de uma dinâmica característica de uma relação ontológica do trabalho do homem com a natureza.

As compreensões apresentadas sobre trabalho, emprego e natureza relacionam-se com perspectivas de Educação Ambiental, em que não há uma criticidade das questões ambientais. Não há uma articulação da relação entre o homem e a natureza, por meio do trabalho, como processo de transformação da natureza pelo homem que, por sua vez, o transforma também. Essa interação ocorre por meio de um equilíbrio na utilização dos recursos naturais, com foco nas reais necessidades humanas. Dessa forma, essas compreensões podem ser associadas à corrente Conservacionista/Recursista e à corrente Resolutiva de Educação Ambiental, descritas por Sauvé (2005), bem como às concepções da Educação Ambiental Convencional, criticadas por Loureiro (2005) e Guimarães (2004). 
A opinião do participante GA10 expressa bem tais concepções ao descrever sobre sua atividade profissional:

Ah, eu acho que primeiramente ser ético, se trabalhar numa indústria ter ética de planejar e organizar as ações dentro dela voltadas para o meio ambiente, né. Também, também pra gestão, pro crescimento da indústria mais, e conservar, preservar o meio ambiente conforme for atuar, conforme o campo de atuação (Part. GA10).

Essas compreensões mostram que o trabalho, sob o ponto de vista ontológico, não é compreendido, acarretando um rompimento da interação humana com a natureza. O processo de alienação, sustentado pela ideologia dominante, distorce a característica humana de interação com a natureza com um foco voltado ao consumo e não às necessidades humanas reais. Ocorrem uma centralidade e cultura no consumo, promovidas pelo capitalismo, que fazem as pessoas perderem as ligações estreitas com a natureza (MAGDOFF \& FOSTER, 2011). Conforme Marx (1996), o produto do trabalho e a relação do trabalhador com a produção tornam-se estranhos ao homem e à natureza.

$\mathrm{Na}$ unidade de análise "Perspectiva interdisciplinar", considerou-se como ocorre a processualidade da relação, através da aproximação entre as disciplinas, entre as diferentes áreas do conhecimento e como as concepções de homem, natureza e trabalho são entendidas nessa relação. A aproximação realizada entre disciplinas e as questões ambientais são assim expressas na opinião do participante GA9:

Fazem, até agora mesmo nós estamos vendo Toxicologia, então a gente tem que entender como age a toxina no organismo, então, o professor sempre tenta puxar um pouco pro lado ambiental. Então, até nós vamos apresentar um trabalho e ele quer que a gente pegue alguma toxina que afete o meio ambiente (Part. GA9).

Conforme sua opinião, as aproximações ocorrem entre disciplinas e a questão ambiental. $O$ mesmo participante, ao ser perguntado sobre as aproximações envolvendo também aspectos sociais e econômicos, por exemplo, atuando em uma empresa, diz que:

Eu acredito que sim, porque na verdade o gestor ambiental deveria cuidar dessa parte, não é porque eles estão fora da empresa que não é responsabilidade da empresa impactar esse local, seria responsabilidade da empresa sim. A empresa deveria agir com essa comunidade, no caso. Na verdade a gente percebe agora que até as empresas estão tentando se Revbea, São Paulo, V. 13, № 2: 195-213, 2018. 
adequar porque é um fato positivo. Porque agora nós temos um mercado também que procura os produtos com relação que a empresa tem alguma, como que posso dizer, que a empresa seja ecologicamente correta. Então a maioria das empresas estão se adequando, já para usar esse marketing para atingir mais esse público, que já é outra visão que eles estão tendo. Então eu acho que teria que ser uma jogadinha de marketing com a empresa e mostrar para eles o custo benefício que eles estariam tendo fazendo essa nova qualificação na empresa (Part. GA9).

No entendimento desse participante, uma empresa possui responsabilidades ao tratar de questões sociais com o gestor ambiental, tendo um papel central neste processo. Entretanto, na sua compreensão, o tratamento dessas questões envolve a lógica do mercado, com a empresa utilizando práticas que seriam ecologicamente corretas com estratégia de marketing, ou seja, uma compreensão dentro da lógica do capitalismo. 0 marketing ambiental é mais uma das estratégias para a manutenção do princípio do lucro no capitalismo. Trata-se de mais um mecanismo ideológico em que o papel das classes sociais é omitido do processo, aparecendo como uma falácia que oculta a divisão de classes, a exploração, o consumismo, dentre outras consequências. Faz parte de uma lógica em que o capitalismo torna-se meio e fim em si mesmo para a sua manutenção, ao gerar lucros, reaquecendo a economia, com a necessidade diária do aumento da produção e consumo (LOUREIRO, 2009).

A fala do participante GA5, ao tratar desse assunto, também mostra uma compreensão de acordo com a lógica do mercado. Diz ele que:

Até porque a empresa, muitas vezes, chega, é um pouco, tem um pouco de culpa nesses problemas gerados na região. Acho que cabe à empresa também tentar ajudar a melhorar [...] eu acho que essa parte é bem complicada até, mas acho que tem que fazer com que a empresa pense também que é um investimento, que, se investir em menos poluição ambiental, vai, pode acabar gastando menos com outras multas e coisas relacionadas a esse respeito (Part. GA5).

Essa fala expressa a ideologia dominante, pois pensar em investimento no sentido de poluir menos, ocasionando a diminuição de outros gastos, expressa uma compreensão de que as questões ambientais podem ser tratadas essencialmente no plano de lucros e custos das empresas. Conforme Altvater (1995), as estruturas econômicas permitem ser sustentáveis apenas de modo condicionado, ou seja, quando não colidem com o princípio do lucro e da competitividade. 
O participante GA10 expressa a sua compreensão a respeito das aproximações envolvendo também aspectos sociais e econômicos ao atuar em uma empresa:

Eu acho que é conscientizando e fazendo a empresa e os donos, os gerentes, proprietários entenderem que a questão ambiental é importante e que se tu não arcar com o custo para prevenir poluição, ou prevenir qualquer dano que pode gerar, a tua empresa, tu vai arcar com algum custo para remediar aquilo que tu prejudicar (Part. GA10).

Essa opinião expressa novamente que os aspectos sociais, nas aproximações entre disciplinas, estão de acordo com a lógica do mercado envolvendo os custos existentes nas empresas e as ações de prevenir ou remediar, no que se referem às questões ambientais. As falas dos alunos não expressam uma relação das diferentes áreas do conhecimento com sua característica histórica, no sentido de compreender a dinâmica do processo de produção e as conexões econômicas e políticas existentes.

A opinião do participante GA1, quando se expressa sobre o exercício da profissão, exemplifica isso:

É fazer gerenciamento também de uma indústria, a produção mais limpa também que tu pode mudar algumas coisas que vem trazer lucros para o empresário como o meio ambiente (Part. GA1).

Embora as falas tenham expressado que há aproximações entre as disciplinas e a questão ambiental, bem como com questões sociais, os alunos não apresentam compreensões de que a lógica do sistema capitalista possui um foco na produção para o mercado e não para as reais necessidades humanas, e que, nesse processo, o trabalho humano possui uma centralidade, pois através dele o homem transforma a natureza e, por sua vez, transformase.

Assim, não se verifica uma formação com aspectos críticos e emancipatórios dos alunos, que permita a superação do caráter contraditório existente, em que as relações econômicas aparecem superficialmente (BOTTOMORE, 1988). Permite também compreensão de que os sujeitos são representados por classes sociais que são antagônicas e que fazem parte do processo de luta de classes. Isso permitiria a superação do processo de alienação do homem em relação à natureza, que ocorre por meio do processo de trabalho (MARX, 1996). 
São perspectivas que estão de acordo com a Ecopedagogia, pois possuem como base o pensamento crítico, que promove a transformação e a construção da sociedade, envolvendo a individualidade e a coletividade com foco interdisciplinar na relação entre o homem e a natureza (AVANZI, 2004). Também estão de acordo com as compreensões de preservação e defesa do equilíbrio ecológico para as gerações de hoje e futuras, como compromisso ético e dever do poder público e da coletividade, conforme a Educação Ambiental Emancipatória e Transformadora de Quintas (2004).

\section{Considerações finais}

As concepções sobre homem, natureza e trabalho que emergiram no curso de Tecnologia em Gestão Ambiental mostram uma compreensão da natureza separada do homem. Isso se evidenciou nas falas dos alunos, ao expressarem que o homem causa impactos à natureza e que o gestor ambiental atua diminuindo os impactos ambientais e relacionando-os com o aumento dos lucros das empresas, ou seja, uma compreensão que está de acordo com a lógica capitalista. É uma compreensão que considera possível conciliar o contraditório, ou seja, a lógica de produção para o consumo com os recursos limitados existentes na natureza. Essa compreensão de cisão entre o homem e a natureza aparece também ao considerar que a Educação Ambiental seja um ato de conscientizar e orientar as pessoas para diminuir os impactos ambientais.

$\mathrm{Na}$ relação existente entre trabalho, emprego e natureza, ficou evidenciada a dificuldade na diferenciação entre trabalho e emprego. As ideias apresentadas vincularam-se a uma renda, à estabilidade, à realização pessoal e/ou a obrigações. Evidencia-se a compreensão de que o trabalho e o emprego têm foco no mercado, que possui suas demandas. A relação entre trabalho, emprego e natureza também apareceu como um processo de exploração da natureza pelo homem, causando impactos.

$\mathrm{Na}$ análise sobre a perspectiva interdisciplinar, as compreensões mostram o envolvimento com a lógica do mercado, como uma empresa utilizando práticas, que seriam ecologicamente corretas, como estratégias de marketing, ou seja, uma compreensão do marketing ambiental como uma das formas de manter a lógica capitalista. Também expressaram a ideologia dominante no sentido de práticas consideradas ambientalmente corretas, como poluir menos ocasionando a diminuição de outros gastos, ou seja, compreensões que mostram que a atividade do gestor ambiental pode ser tratada somente no plano de lucros e custos das empresas.

As compreensões de Educação Ambiental verificadas estão relacionadas a aspectos direcionados a práticas que envolvem a preservação e mitigação; o foco é voltado a medidas de conscientização dos sujeitos, ou seja, uma compreensão de que a Educação Ambiental permitiria a conscientização para diminuir os impactos ambientais. As compreensões de Educação Profissional apresentadas foram aquelas relacionadas a um processo formativo

revista brasileira educação ambiental 
que os qualifica para um "mercado de trabalho", que estão de acordo com as necessidades do processo produtivo. Também, compreensões em que há uma separação entre o trabalho manual e o trabalho intelectual, conforme o modo de produção capitalista.

O trabalho, em sua essência ontológica, tratado como uma relação metabólica entre o homem e a natureza, deve ser um elo para que a Educação Ambiental e Educação Profissional dialoguem na construção de sujeitos críticos e emancipados em suas relações sociais e ambientais.

\section{Referências}

ALTVATER, E. O preço da riqueza. São Paulo: Editora UNESP, 1995.

AVANZI, M.R. Ecopedagogia. In: LAYRARGUES, P.P. (coord.) Identidades da Educação Ambiental Brasileira. Brasília, Ministério do Meio Ambiente, 2004.

BARDIN, L. Análise de Conteúdo. Lisboa: Edições 70, 1977.

BRASIL. Lei no 11.892 - de 29 de dezembro de 2008. Institui a Rede Federal de Educação Profissional, Científica e Tecnológica, cria os Institutos Federais de Educação, Ciência e Tecnologia, e dá outras providências. Disponível em: $<$ http://www.planalto.gov.br/ccivil 03/ ato2007-2010/2008/lei//11892.htm>.

Acesso em: 15 jul. 2012.

BRASIL. Resolução n. 3 do CNE, de 18 de dezembro de 2002. Institui as Diretrizes Curriculares Nacionais Gerais para a organização e o funcionamento dos cursos superiores de tecnologia. Brasília, DF, 2002. Disponível em: $<$ http://portal.mec.gov.br/cne/arquivos/pdf/CP032002.pdf>. Acesso em: 18 ago. 2012.

BOTTOMORE, T. Dicionário do pensamento marxista. Rio de Janeiro: Zahar Ed., 1988.

CARVALHO, I.C.M. Educação Ambiental: a formação do sujeito ecológico. São Paulo: Cortez, 2004.

FRANCO, M.L.P. Análise de Conteúdo. Brasília, Líber Livro Editora, $2^{a}$ ed., 2005.

FOSTER, J.B, A ecologia de Marx: materialismo e natureza. $3^{\text {a }}$ ed. Rio de Janeiro: Civilização Brasileira, 2011.

FRIGOTTO, G, A Relação da Educação Profissional e Tecnológica com a Universalização da Educação Básica. Educação \& Sociedade, v. 28, n. 100, 2007.

FRIGOTTO, G.; CIAVATTA, M.P.F.; RAMOS, M.N. A política de educação profissional no governo Lula: um percurso histórico controvertido. Educação \& Sociedade, vol. 26, n. 92, 2005.

GIL, A.C. Métodos e Técnicas de Pesquisa Social. São Paulo: Atlas, 2008. 
GUIMARÃES, M, Educação Ambiental Crítica. In: LAYRARGUES, P.P. (coord.) Identidades da Educação Ambiental Brasileira. Brasília, Ministério do Meio Ambiente, 2004.

KUENZER, A.Z. A educação profissional nos anos 2000: a dimensão subordinada das políticas de inclusão. Educação \&Sociedade, vol. 27, n. 96, 2006.

KUENZER, A.Z. O ensino médio no plano nacional de educação 2011-2020: superando a década perdida? Educação \& Sociedade, v. 31, n. 112, 2010.

KUENZER, A.Z.; GRABOWSKI, G, Educação Profissional: desafios para a construção de um projeto para os que vivem do trabalho. Perspectiva, v. 24, n. 1, 2006.

LOUREIRO, C.F.B, Educação ambiental transformadora. In: LAYRARGUES, P.P. (coord.) Identidades da Educação Ambiental Brasileira. Brasília, Ministério do Meio Ambiente, 2004.

LOUREIRO, C.F.B, Trajetórias e Fundamentos da Educação Ambiental. São Paulo: Cortez, 2009.

MAGDOFF, F; FOSTER, J.B, What every environmentalist needs to know about capitalism. New York: Monthly Review Press, 2011.

MARX, K, O Capital: Crítica da economia política. São Paulo: Nova Cultural, 1996.

OTRANTO, C.R, Criação e implantação dos institutos federais de educação, ciência e tecnologia - IFETs. Revista RETTA (PPGEA/UFRRJ), Rio de Janeiro, n. 1, 2010.

QUINTAS, J.S, Educação no processo de gestão ambiental: uma proposta de educação ambiental transformadora e emancipatória. In: LAYRARGUES, P. P. (coord.) Identidades da Educação Ambiental Brasileira. Brasília, Ministério do Meio Ambiente, 2004.

RUSCHEINSKY, A. Atores sociais e meio ambiente. In: LAYRARGUES, P. P. (coord.) Identidades da Educação Ambiental Brasileira. Brasília, Ministério do Meio Ambiente, 2004.

SAUVÉ, L. Uma cartografia das correntes em educação ambiental. In: SATO, M; CARVALHO, I.C.M. (orgs.) Educação Ambiental: pesquisas e desafios. Porto Alegre: Artmed, 2005. 